\title{
Endocrine toxicity of cancer immunotherapy: clinical challenges
}

\author{
Bliss Anderson and Daniel L Morganstein \\ Department of Endocrinology, Chelsea and Westminster Hospital NHS Foundation Trust, London, UK
}

Correspondence should be addressed to D L Morganstein: d.morganstein@imperial.ac.uk

\begin{abstract}
Immune checkpoint inhibitors are now widely used in the treatment of multiple cancers. The major toxicities of these treatments are termed immune-related adverse events and endocrine dysfunction is common. Thyroid disease, hypopituitarism and a form of diabetes resembling type 1 diabetes are now all well described, with different patterns emerging with different checkpoint inhibitors. We review the presentation and management of the common endocrine immune-related adverse events, and discuss a number of recent advances in the understanding of these important, potentially life threatening toxicities. We also discuss some remaining dilemmas in management.
\end{abstract}

\author{
Key Words \\ - checkpoint inhibitor \\ - cancer \\ - thyroiditis \\ - hypophysitis \\ - diabetes
}

\section{Introduction}

Immunotherapy with immune checkpoint inhibitors (CPI's) has been revolutionising the management of advanced malignancies with their success in improving overall patient survival $(1,2)$. CPI's are antibodies that block T-cell signalling pathways, that otherwise suppress immune responses to cancer cells, thereby acting to promote an anti-tumour immune response. Current agents are monoclonal antibodies targeting either cytotoxic T lymphocyte antigen 4 (anti-CTLA4), programmed cell death-1 (anti-PD-1) or its ligand PD-L1 (anti-PD-L1) to potentiate anti-tumour immune responses. Such is their success, they have now become first-line therapy for metastatic melanoma, non-small cell lung cancer and renal cell carcinoma (3). They are now licensed for use in multiple other cancers, including Head and Neck cancers.

Unfortunately superior clinical response is often associated with treatment toxicity termed immunerelated adverse effects (IRAEs) and can involve multiple organs including skin, lung, liver and bowel (4). Whilst the exact mechanism of these toxicities is not yet fully understood, it is thought to involve a reduction in tolerance, through inhibition of the immune checkpoints, resulting in autoimmunity towards normal tissues (Fig. 1). Side effects can range from mild to life threatening. The latter can include severe colitis, pneumonitis and cardiomyopathies (5). Whilst in mild cases treatment can often continue, the mainstay of moderate and severe IRAE's involves cessation of CPI therapy and immunosuppression with glucocorticoids as first-line agents (5).

Adverse effects have been reported more frequently with CTLA-4 inhibitors (e.g. ipilimumab) vs PD-1 inhibitors (e.g. pembrolizumab, nivolumab). Whilst it has been shown that combination therapy with both agents show superior response rates, but also carries a greater risk of such IRAE's (6).

Endocrinopathy has emerged as an important group of IRAEs. Importantly, whilst most IRAE's are reversible with prompt treatment cessation and glucocorticoids treatment, endocrinopathies usually persist and often require lifelong hormonal replacement. Untreated endocrinopathy can be life threatening. Whilst both CTLA-4 and PD-1 inhibitors are associated most commonly with thyroid dysfunction, hypophysitis resulting in adrenal insufficiency, and insulin-dependent 


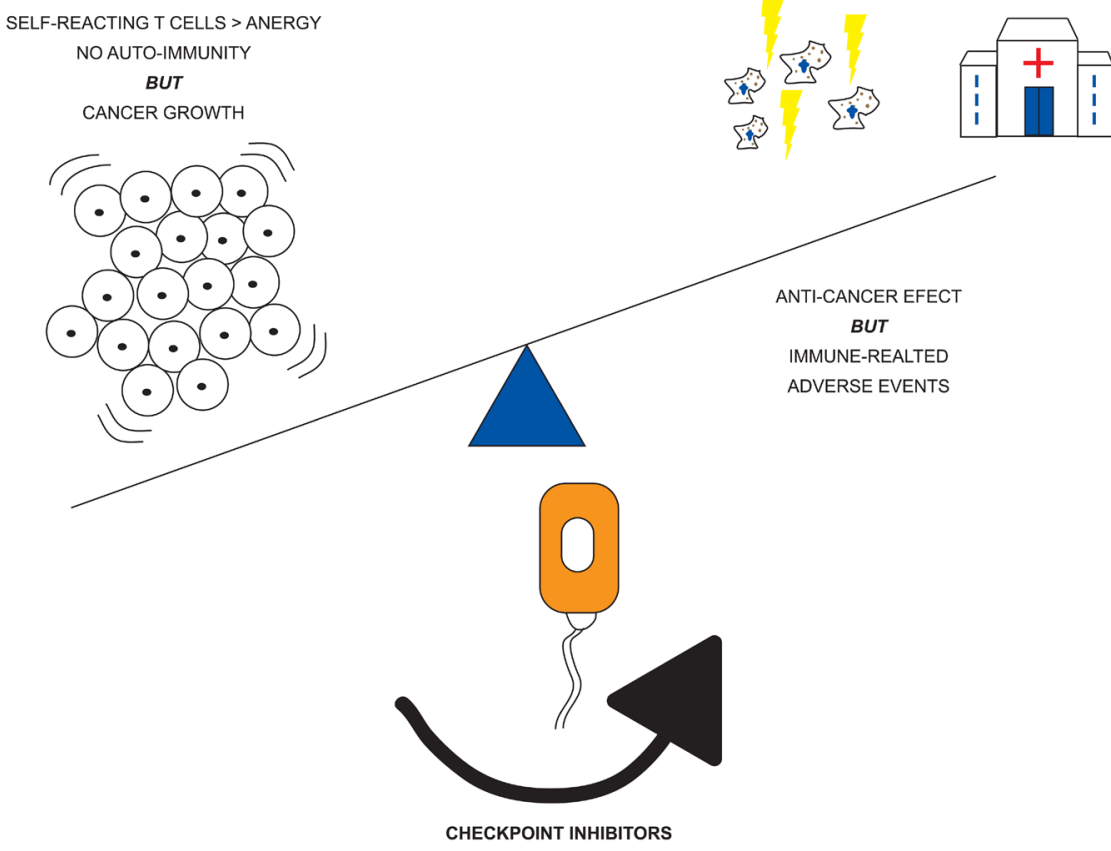

\section{Figure 1}

Graphic illustrating checkpoint inhibitor action to shift immune response. Without treatment self and tumour reacting T-cells are driven to anergy and unchecked tumour growth. Following treatment, the anti-cancer immune response is upregulated leading to controlled tumour growth, but increased risk of self-reacting $T$ cells contributing to immune-related adverse events. diabetes also occur (7). Detection of endocrinopathy can be difficult given their subtle, non-specific symptoms such as fatigue and may be a challenge to distinguish them from pre-existing comorbidities. Therefore clinicians need to be vigilant to ensure rapid recognition and treatment, especially in those individuals with increased risk of autoimmune reactions. The major endocrine toxicities from checkpoint inhibitors and their management are summarised in Table 1.

This review will focus on recent advances in our knowledge of endocrinopathy following checkpoint inhibitor therapy. Current areas of clinical uncertainty, ongoing controversies and changes in the management approaches will be discussed.

\section{Pituitary}

Two distinct patterns of pituitary involvement have been described. Patients treated with the CTLA-4 inhibitor Ipilimumab can develop hypophysitis in around $10 \%$ of cases, which can present with the classical features of headache, fatigue and pituitary enlargement seen on brain imaging $(8,9,10,11,12)$. Pituitary dysfunction is variable but ACTH deficiency seems essentially universal $(13,14)$. In contrast, the PD-1 and PD-L1 inhibitors result less commonly in pituitary involvement $(\sim 1 \%)$, and are reported to result in isolated ACTH deficiency, without other features of hypophysitis $(15,16)$. However the literature can be confusing, as hypopituitarism and hypophysitis are frequently used interchangeably (17) and there is a need for standardised case definitions (16).

\section{Role for high dose steroids and management of hypopituitarism}

By extrapolation from other inflammatory pituitary conditions, initially patients presenting with ipilimumabinduced hypophysitis were initially treated with high dose glucocorticoids ( typically $1 \mathrm{mg} / \mathrm{kg}$ of methylprednisolone). In addition, early case reports frequently described pituitary enlargement on MRI associated with headache $(18,19,20,21,22)$, so glucocorticoids may have been indicated to prevent further pituitary enlargement. When patients present with signs or symptoms of adrenal insufficiency, stress doses of glucocorticoids are also indicated (23).

However, there is now evidence that treatment with high dose glucocorticoids does not improve pituitary function (24). More concerningly, melanoma patients with ipilimumab-induced hypophysitis treated with high dose glucocorticoids had worse oncological outcomes than those receiving replacement doses. There was a shorter time to treatment failure and overall survival in those receiving high dose steroids (25). This is notable as studies in patients with non-endocrine immune-related toxicity have not shown an association with the use of high dose steroids and oncological outcomes (26).

Therefore current practice is to reserve high dose corticosteroids for those presenting with adrenal crisis
This work is licensed under a Creative Commons Attribution-NonCommercial 4.0 International License. ded from Bioscientifica.com at 04/26/2023 02:15:14PM via free access 

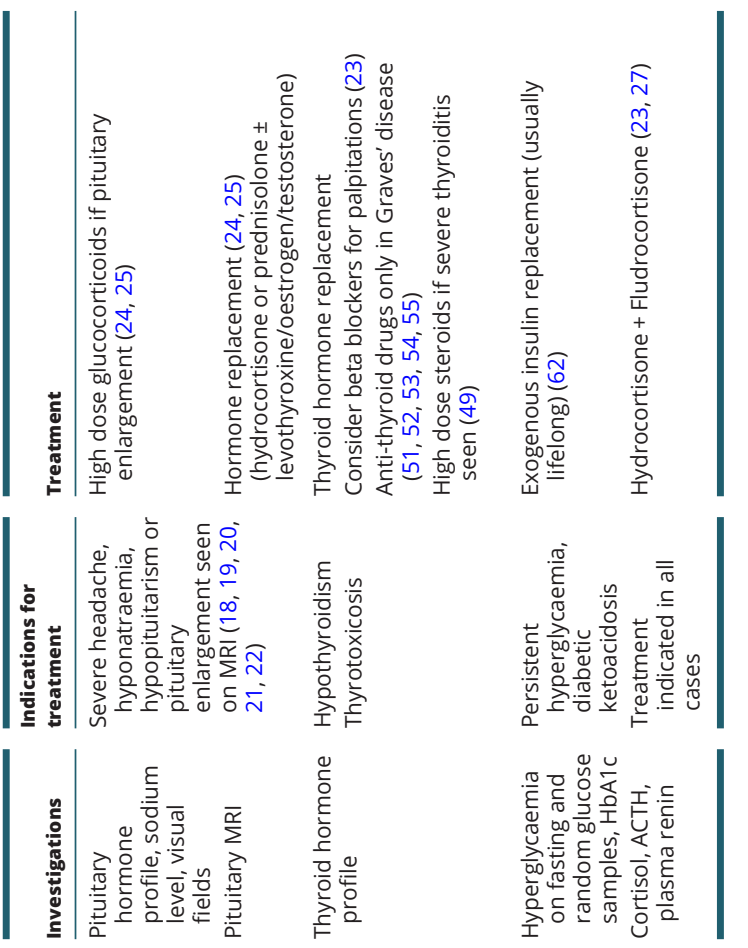

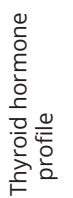
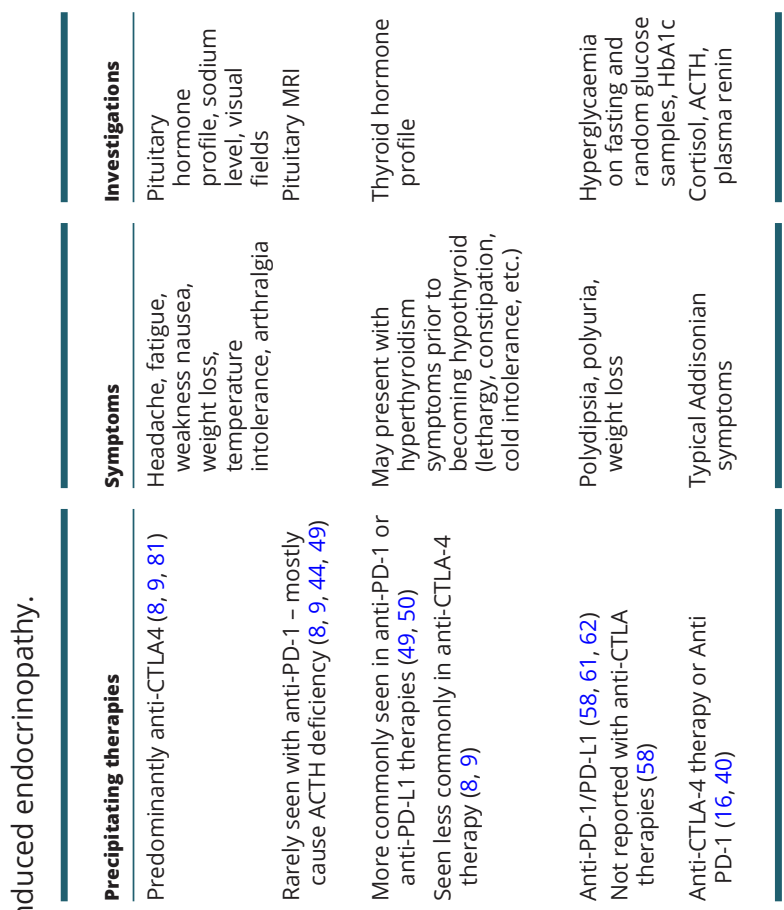

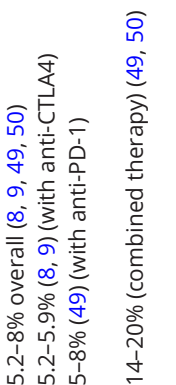

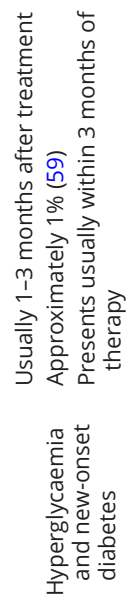

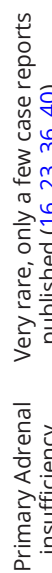

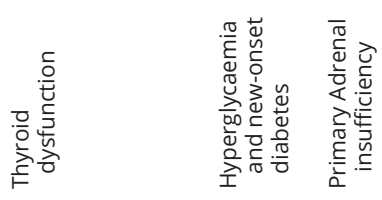

or with significant pituitary enlargement. Other patients can be commenced directly on replacement doses of corticosteroids (e.g. hydrocortisone $20 \mathrm{mg}$ daily in divided doses or prednisolone $3 \mathrm{mg}$ once daily (27)). Indeed there are now reports of the safety of managing such patients on an out-patient basis (28).

Thyroxine is replaced by standard approaches, following glucocorticoids, and testosterone or oestrogen replacement may also be required. Notably growth hormone replacement is contra-indicated in those with active or recent history of cancer (29), so assessment of growth hormone levels is not recommended.

\section{Prediction of hypophysitis}

Given the potentially severe impact of hypopituitarism and adrenal insufficiency, early detection of hypophysitis is vital. There has therefore been interest in biomarkers to predict its onset. The summary of product characteristics for checkpoint inhibitor recommend regular testing of thyroid function during treatment. Attempting to predict the onset of hypophysitis with subtle changes to thyroid function tests has been examined. Two studies have described a fall in TSH in the cycle of treatment prior to the onset of ipilimumab-induced hypophysitis $(9,30)$, although a larger series showed that a fall in free $\mathrm{T} 4$ at cycle 3 of ipilimumab had the best predictive value for subsequent hypophysitis (13). The later study used a clinical definition of hypophysitis that required at least one other feature apart from secondary hypothyroidism, confirming that a fall in $\mathrm{T} 4$ levels may precede hypophysitis. However, as pituitary involvement in PD-1/PD-L1 inhibitor therapy is usually limited to ACTH deficiency, thyroid function would not be expected to be a useful predictor in this cohort.

The development of autoantibodies has been described in a number of IRAEs, including diabetes and hypophysitis $(31,32,33)$. Two studies have now reported the development of auto-antibodies in hypophysitis (34, 35 ), although notably there was no common antibodies described, and both studies included patients with both ipilimumab hypophysitis and the more limited ACTH deficiency with nivolumab or pembrolizumab. A further study suggested that hypophysitis was more common in certain HLA types, most notably DR15 (36), although again the hypophysitis cohort was heterogeneous.

Currently, there are no reliable biomarkers for risk of hypophysitis, and given the protean presentation of hypopituitarism, adrenal insufficiency and hypophysitis, careful clinical assessment is required $(9,23,37)$. 


\section{Longer term prognosis of hypophysitis}

To date, most series have not reported recovery of ACTH function, although recovery of other pituitary axis is reported $(9,37,38)$. As discussed previously, high dose steroids do not improve pituitary function recovery (24). Nevertheless there have been occasional reports of spontaneous recovery of pituitary function, including ACTH secretion $(39,40)$, so clinical and biochemical assessment over time is advised.

A third of patients receiving a CPI will require high dose glucocorticoids for management of non-endocrine IRAEs, at doses associated with adrenal suppression $(26,41)$. Therefore, caution is also required when stopping glucocorticoids in these patients in case of the development of ACTH deficiency.

\section{Thyroid}

The thyroid is the most common endocrine gland to be affected by checkpoint inhibitors, with PD-1 and PD-L1 inhibitors showing a higher rate of clinically overt disease than ipilimumab $(42,43,44)$. Hypothyroidism is common, as is transient thyrotoxicosis, usually, but not always, followed by subsequent hypothyroidism. Hypothyroidism is managed with levothyroxine replacement as per standard practice. Hyperthyroidism can usually be managed symptomatically with beta blockers, although steroids are occasionally required, with close monitoring for progression to hypothyroidism (23).

Although symptoms should prompt assessment, thyroid dysfunction is usually detected on routine treatment monitoring blood tests. Both a higher patient BMI or a higher baseline TSH may be associated with an increased risk of thyroid dysfunction $(43,45)$. Prior use of a tyrosine kinase inhibitor also increases the risk of thyroid dysfunction (46). Raised levels of cytokines including IL-1 $\beta$ and IL-2 pre-treatment, as well as an early rise in thyroglobulin have been reported to predict thyroiditis (47), although the clinical utility of these markers is unclear. FDG-PET uptake in the thyroid is also associated with subsequent hypothyroidism (48).

Notably, whilst onset can occur as early as 3 weeks post therapy initiation, most cases present 1-2 months following but it has been shown to present as late as 3 years $(49,50)$.

\section{Thyroiditis vs Graves'}

The main clinical challenge in thyroid practice is detecting the rare patient with Graves' disease and distinguishing this from the more common thyroiditis $(51,52,53)$, which has been described with both PD-1 and CTLA-4 inhibitors. Those with thyrotoxicosis should therefore be investigated with TSH Receptor antibodies and clinicians should consider an uptake scan to distinguish Graves' from destructive thyroiditis, taking into account that many patients will have received recent intravenous iodine contrast. However, as the thyrotoxicosis in thyroiditis is usually short lived, these investigations may only be required in prolonged thyrotoxicosis (23). The presence of thyroid eye disease may also alert the clinician to the possibility of Graves' as a cause of thyrotoxicosis $(54,55)$. First-line management is with anti-thyroid drugs such as carbimazole.

\section{Diabetes}

A form of insulin-requiring diabetes is described in around $1-2 \%$ of patients receiving PD-1 or PD-L1 inhibitors, alone or in combination with ipilimumab $(33,56,57$, $58,59)$. Features closely resemble Type 1 diabetes, with low c-peptide levels, whilst GAD antibodies are present in around $50 \%$ of cases, a notably lower proportion than in spontaneous type 1 diabetes $(59,60)$.

Several case studies demonstrate that patients given anti-PD-1 therapy present with either severe hyperglycaemia or more commonly, diabetic ketoacidosis (DKA) $(58,61)$. A large scale review of 71 case reports found that $76 \%$ presented with DKA with a mean capillary blood glucose of $33.4 \pm 11.5 \mathrm{mmol} / \mathrm{L}$ and HbA1c of $62 \pm 0.3$ $\mathrm{mmol} / \mathrm{mol}$ (62). $71 \%$ of cases developed within 3 months of first exposure to anti-PD-1 or anti-PD-L1 therapy. However, this review found no correlation between $\mathrm{HbA1c}$ and time of diabetes diagnosis.

Notably the onset is frequently rapid, with some showing features compatible with fulminant type 1 diabetes, progressing from euglycaemia to DKA in a matter of days $(63,64,65,66,67,68,69,70,71)$. Whilst those with very rapid onset are less likely to have classical diabetes autoantibodies, and frequently show elevations of pancreatic enzymes (60), other case series have suggested that autoantibodies were in fact associated with a shorter onset of diabetes (62). Therefore the clinical utility of autoantibodies is unclear, and close attention to any red flag symptoms such as fatigue, thirst or polyuria is required, with prompt assessment of glucose and ketones to try to avoid missing a diagnosis of DKA. Pre-existing type 2 diabetes may be a risk factor for CPI-induced diabetes, 
- Checkpoint inhibitors (CPIs) are now widely used in oncology treatment however, their use is often associated with treatment toxicity termed 'immune related adverse events' (IRAE).

- Endocrinopathies are amongst the more common IRAEs and usually result in long term hormone deficiencies.

- Detection of endocrinopathy may be challenging due to subtle, non specific symptoms (see Table 1).

- Pituitary dysfunction can either be seen as an isolated ACTH deficiency or a more classical hypophysitis (hypopituitarism, headaches, \pm pituitary enlargement) with PD-L1 and CTLA4 inhibitors respectively.

- High dose glucocorticoids do not improve immunotherapy-induced hypophysitis and may result in worse oncological outcomes versus those receiving only physiological replacement.

- Hypothyroidism and transient thyrotoxicosis, followed by hypothyroidism, is the most common endocrinopathy caused by CPIs.

- Distinguishing between thyroiditis associated with CPIs and Grave's disease can be challenging and may require TSH receptor antibody levels and uptake scans to determine diagnosis.

- Insulin-requiring diabetes has been described with anti-PD1 therapy and may first present with rapid onset diabetic ketoacidosis (DKA).

- A third of patients receiving CPIs require high dose steroids for non-endocrine IRAEs and therefore deteriorating hyperglycaemia needs careful evaluation to determine whether it is steroid-induced or CPI-induced.

- Development of endocrinopathy is associated with longer overall survival versus those patients without and therefore, lifelong hormonal treatment with specialist care from both endocrinologists and oncologists is required.

with $7-10 \%$ of those with type 2 diabetes showing deterioration in control, often requiring insulin (56).

Corticosteroids do not prevent progression to insulin deficiency (72), although insulin deficiency is not universal with one case describing preservation of insulin secretion after cessation of the checkpoint inhibitor (73), and one patient with prior IA2 antibodies able to come off insulin (32).

\section{Steroids and CPI diabetes}

A potential confounder is that around $30 \%$ of patients receiving CPIs will require high dose steroids for nonendocrine IRAEs $(26,41)$, with studies suggest that $6-8 \%$ of CPI treated patients go on to develop steroid-induced hyperglycaemia $(41,74)$. As such, patients with new-onset or deteriorating hyperglycaemia after CPI treatment need careful evaluation, including a history of steroid use and assessment for ketosis to ensure that CPI-induced diabetes is not missed, placing patients at particular risk of DKA.

\section{Clinical presentation}

\section{Importance of fatigue as red flag}

Fatigue is a common symptom in cancer, also being frequent with conventional treatments such as cytotoxic chemotherapy. Close to $40 \%$ of patients treated with
PD-1/PD-L1 inhibitors have been reported to have fatigue (75), most of whom will not have endocrinopathy. However, fatigue can also be a presentation of adrenal insufficiency (either primary or due to pituitary involvement), thyroid dysfunction and diabetes. As adrenal insufficiency and diabetes leading to DKA can be life threatening, it is vital that onset of fatigue in patients who have received a checkpoint inhibitor leads to prompt investigation for endocrinopathy.

Equally though, it is important to recognise that fatigue can occur, as a result of cancer or its treatment, without endocrine dysfunction, so a thorough evaluation is required before starting hormone replacement.

\section{Long term implications}

Unlike most other IRAEs, endocrinopathy is usually nonreversible and is expected to require long term hormone replacement. Hypopituitarism is associated with reduced quality of life, although careful avoidance of overreplacement with glucocorticoids improves this (76). Type 1 diabetes is also well known to be associated with reduced quality of life (77). Both conditions need life long specialist care.

This is particularly important as it is now emerging that the development of endocrinopathy, specifically hypophysitis or thyroid dysfunction, is associated with
This work is licensed under a Creative Commons Attribution-NonCommercial 4.0 International License. ded from Bioscientifica.com at 04/26/2023 02:15:14PM 
better cancer outcomes and longer overall survival than controls without endocrinopathy $(78,79,80)$. Therefore the cohort of long term survivors is likely to include many with endocrinopathy, with the associated need for hormone replacement, impact on quality of life and need for specialist follow up.

\section{Conclusions}

Endocrine dysfunction is among the more frequent immune-related adverse events following checkpoint inhibitor treatment, usually resulting in life long hormone deficiencies. The presentation can be subtle, and a careful endocrine assessment of patients presenting with red-flag symptoms including fatigue is required. Those with confirmed endocrinopathy, especially adrenal insufficiency and diabetes, need ongoing endocrine input to optimise treatment.

\section{Declaration of interest}

$B$ A reports no conflict of interest. D M has received speaker and advisory fees from BMS, MSD and Roche.

\section{Funding}

This work did not receive any specific grant from any funding agency in the public, commercial or not-for-profit sector.

\section{References}

1 Drake CG, Lipson EJ \& Brahmer JR. Breathing new life into immunotherapy: review of melanoma, lung and kidney cancer. Nature Reviews: Clinical Oncology 201411 24-37. (https://doi. org/10.1038/nrclinonc.2013.208)

2 Farkona S, Diamandis EP \& Blasutig IM. Cancer immunotherapy: the beginning of the end of cancer? BMC Medicine 201614 73. (https:// doi.org/10.1186/s12916-016-0623-5)

3 Force J \& Salama AK. First-line treatment of metastatic melanoma: role of nivolumab. ImmunoTargets and Therapy 20176 1-10. (https:// doi.org/10.2147/ITT.S110479)

4 Spiers L, Coupe N \& Payne M. Toxicities associated with checkpoint inhibitors - an overview. Rheumatology 201958 vii7-vii16. (https:// doi.org/10.1093/rheumatology/kez418)

5 Haanen JBAG, Carbonnel F, Robert C, Kerr KM, Peters S, Larkin J, Jordan K \& ESMO Guidelines Committee. Management of toxicities from immunotherapy: ESMO Clinical Practice Guidelines for diagnosis, treatment and follow-up. Annals of Oncology 201728 iv119-iv142. (https://doi.org/10.1093/annonc/mdx225)

6 Hodi FS, Chiarion-Sileni V, Gonzalez R, Grob J-J, Rutkowski P, Cowey CL, Lao CD, Schadendorf D, Wagstaff J, Dummer R, et al. Nivolumab plus ipilimumab or nivolumab alone versus ipilimumab alone in advanced melanoma (CheckMate 067): 4-year outcomes of a multicentre, randomised, phase 3 trial. Lancet Oncology 201819 1480-1492. (https://doi.org/10.1016/S1470-2045(18)30700-9)
7 Bai X, Lin X, Zheng K, Chen X, Wu X, Huang Y \& Zhuang Y. Mapping endocrine toxicity spectrum of immune checkpoint inhibitors: a disproportionality analysis using the WHO Adverse Drug Reaction Database, VigiBase. Endocrine 202069 670-681. (https://doi.org/10.1007/s12020-020-02355-9)

8 Ryder M, Callahan M, Postow MA, Wolchok J \& Fagin JA. Endocrinerelated adverse events following ipilimumab in patients with advanced melanoma: a comprehensive retrospective review from a single institution. Endocrine-Related Cancer 201421 371-381. (https:// doi.org/10.1530/ERC-13-0499)

9 Faje AT, Sullivan R, Lawrence D, Tritos NA, Fadden R, Klibanski A \& Nachtigall L. Ipilimumab-induced hypophysitis: a detailed longitudinal analysis in a large cohort of patients with metastatic melanoma. Journal of Clinical Endocrinology and Metabolism 201499 4078-4085. (https://doi.org/10.1210/jc.2014-2306)

10 Chodakiewitz Y, Brown S, Boxerman JL, Brody JM \& Rogg JM. Ipilimumab treatment associated pituitary hypophysitis: clinical presentation and imaging diagnosis. Clinical Neurology and Neurosurgery 2014125 125-130. (https://doi.org/10.1016/j. clineuro.2014.06.011)

11 De Sousa SM, Long GV \& Tonks KT. Ipilimumab-induced hypophysitis: early Australian experience. Medical Journal of Australia 2014201 198-199. (https://doi.org/10.5694/mja14.00803)

12 Lammert A, Schneider HJ, Bergmann T, Benck U, Kramer BK, Gartner R, Metzner C, Schofl C \& Berking C. Hypophysitis caused by ipilimumab in cancer patients: hormone replacement or immunosuppressive therapy. Experimental and Clinical Endocrinology and Diabetes 2013121 581-587. (https://doi. org/10.1055/s-0033-1355337)

13 Siddiqui MS, Lai ZM, Spain L, Greener V, Turajlic S, Larkin J \& Morganstein DL. Predicting development of ipilimumab-induced hypophysitis: utility of T4 and TSH index but not TSH. Journal of Endocrinological Investigation 202144 195-203. (https://doi. org/10.1007/s40618-020-01297-3)

14 Albarel F, Gaudy C, Castinetti F, Carré T, Morange I, Conte-Devolx B, Grob JJ \& Brue T. Long-term follow-up of ipilimumab-induced hypophysitis, a common adverse event of the anti-CTLA- 4 antibody in melanoma. European Journal of Endocrinology 2015172 195-204. (https://doi.org/10.1530/EJE-14-0845)

15 Faje A, Reynolds K, Zubiri L, Lawrence D, Cohen JV, Sullivan RJ, Nachtigall LB \& Tritos N. Hypophysitis secondary to nivolumab and pembrolizumab is a clinical entity distinct from ipilimumabassociated hypophysitis. European Journal of Endocrinology 2019181 211-219. (https://doi.org/10.1530/EJE-19-0238)

16 Percik R, Shlomai G, Tirosh A, Tirosh A, Leibowitz-Amit R, Eshet Y, Greenberg G, Merlinsky A, Barhod E, Steinberg-Silman Y, et al. Isolated autoimmune adrenocorticotropic hormone deficiency: from a rare disease to the dominant cause of adrenal insufficiency related to check point inhibitors. Autoimmunity Reviews 201919102454. (https://doi.org/10.1016/j.autrev.2019.102454)

17 Garon-Czmil J, Petitpain N, Rouby F, Sassier M, Babai S, YéléhéOkouma M, Weryha G, Klein M \& Gillet P. Immune check point inhibitors-induced hypophysitis: a retrospective analysis of the French pharmacovigilance database. Scientific Reports 2019919419. (https://doi.org/10.1038/s41598-019-56026-5)

18 Rodrigues BT, Otty Z, Sangla K \& Shenoy VV. Ipilimumab-induced autoimmune hypophysitis: a differential for sellar mass lesions. Endocrinology, Diabetes and Metabolism Case Reports 20152014 140098. (https://doi.org/10.1530/EDM-14-0098)

19 Dillard T, Yedinak CG, Alumkal J \& Fleseriu M. Anti-CTLA-4 antibody therapy associated autoimmune hypophysitis: serious immune related adverse events across a spectrum of cancer subtypes. Pituitary 201013 29-38. (https://doi.org/10.1007/s11102-009-0193-z)

20 Torino F, Barnabei A, De Vecchis L, Salvatori R \& Corsello SM. Hypophysitis induced by monoclonal antibodies to cytotoxic T lymphocyte antigen 4: challenges from a new cause of a rare

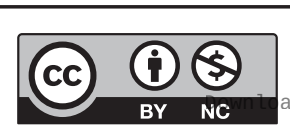

This work is licensed under a Creative Commons Attribution-NonCommercial 4.0 International License. ded from Bioscientifica.com at 04/26/2023 02:15:14PM 
disease. Oncologist 201217 525-535. (https://doi.org/10.1634/ theoncologist.2011-0404)

21 Faje A. Immunotherapy and hypophysitis: clinical presentation, treatment, and biologic insights. Pituitary 201619 82-92. (https:// doi.org/10.1007/s11102-015-0671-4)

22 Carpenter KJ, Murtagh RD, Lilienfeld H, Weber J \& Murtagh FR. Ipilimumab-induced hypophysitis: MR imaging findings. American Journal of Neuroradiology 200930 1751-1753. (https://doi. org/10.3174/ajnr.A1623)

23 Higham CE, Olsson-Brown A, Carroll P, Cooksley T, Larkin J, Lorigan P, Morganstein D, Trainer PJ \& Society for Endocrinology Clinical Committee. SOCIETY FOR ENDOCRINOLOGY ENDOCRINE EMERGENCY GUIDANCE: Acute management of the endocrine complications of checkpoint inhibitor therapy. Endocrine Connections 20187 G1-G7. (https://doi.org/10.1530/EC-18-0068)

24 Min L, Hodi FS, Giobbie-Hurder A, Ott PA, Luke JJ, Donahue H, Davis M, Carroll RS \& Kaiser UB. Systemic high-dose corticosteroid treatment does not improve the outcome of ipilimumab-related hypophysitis: a retrospective cohort study. Clinical Cancer Research 201521 749-755. (https://doi.org/10.1158/1078-0432.CCR-14-2353)

25 Faje AT, Lawrence D, Flaherty K, Freedman C, Fadden R, Rubin K, Cohen J \& Sullivan RJ. High-dose glucocorticoids for the treatment of ipilimumab-induced hypophysitis is associated with reduced survival in patients with melanoma. Cancer 2018124 3706-3714. (https://doi.org/10.1002/cncr.31629)

26 Horvat TZ, Adel NG, Dang TO, Momtaz P, Postow MA, Callahan MK, Carvajal RD, Dickson MA, D'Angelo SP, Woo KM, et al. Immunerelated adverse events, need for systemic immunosuppression, and effects on survival and time to treatment failure in patients with melanoma treated with ipilimumab at Memorial Sloan Kettering Cancer Center. Journal of Clinical Oncology 201533 3193-3198. (https://doi.org/10.1200/JCO.2015.60.8448)

27 Simpson H, Tomlinson J, Wass J, Dean J \& Arlt W. Guidance for the prevention and emergency management of adult patients with adrenal insufficiency. Clinical Medicine 202020 371-378. (https://doi. org/10.7861/clinmed.2019-0324)

28 Cooksley T, Knight T, Gupta A, Higham C, Lorigan P \& Adam S. Emergency ambulatory outpatient management of immunemediated hypophysitis. Supportive Care in Cancer 202028 3995-3999. (https://doi.org/10.1007/s00520-020-05581-z)

29 Yuen KCJ, Heaney AP \& Popovic V. Considering GH replacement for GH-deficient adults with a previous history of cancer: a conundrum for the clinician. Endocrine 201652 194-205. (https://doi. org/10.1007/s12020-015-0840-2)

30 De Sousa SMC, Sheriff N, Tran CH, Menzies AM, Tsang VHM, Long GV \& Tonks KTT. Fall in thyroid stimulating hormone (TSH) may be an early marker of ipilimumab-induced hypophysitis. Pituitary 201821 274-282. (https://doi.org/10.1007/s11102-0180866-6)

31 Way J, Drakaki A, Drexler A \& Freeby M. Anti-PD-L1 therapy and the onset of diabetes mellitus with positive pancreatic autoantibodies. BMJ Case Reports 20172017 bcr2017220415. (https://doi. org/10.1136/bcr-2017-220415)

32 Ohara N, Kobayashi M, Ikeda Y, Hoshi T, Morita S, Kanefuji T, Yagi K, Suda T, Takada T, Hasegawa G, et al. Non-insulin-dependent diabetes mellitus induced by immune checkpoint inhibitor therapy in an insulinoma-associated antigen-2 autoantibody-positive patient with advanced gastric cancer. Internal Medicine 201959 551-556. (https:// doi.org/10.2169/internalmedicine.3208-19)

33 Galligan A, Xu W, Fourlanos S, Nankervis A, Chiang C, Mant AM, Parente P, Rischin D, Krishnamurthy B, Sandhu S, et al. Diabetes associated with immune checkpoint inhibition: presentation and management challenges. Diabetic Medicine 201835 1283-1290. (https://doi.org/10.1111/dme.13762)

34 Tahir SA, Gao J, Miura Y, Blando J, Tidwell RSS, Zhao H, Subudhi SK, Tawbi H, Keung E, Wargo J, et al. Autoimmune antibodies correlate with immune checkpoint therapy-induced toxicities. PNAS 2019116 22246-22251. (https://doi.org/10.1073/pnas.1908079116)

35 Leiter A, Gnjatic S, Fowkes M, Kim-Schulze S, Laface I, Galsky MD \& Gallagher EJ. A common pituitary autoantibody in two patients with immune checkpoint inhibitor-mediated hypophysitis: ZCCHC8. AACE Clinical Case Reports 20206 e151-e160. (https://doi. org/10.4158/ACCR-2019-0585)

36 Yano S, Ashida K, Sakamoto R, Sakaguchi C, Ogata M, Maruyama K, Sakamoto S, Ikeda M, Ohe K, Akasu S, et al. Human leucocyte antigen DR15, a possible predictive marker for immune checkpoint inhibitor-induced secondary adrenal insufficiency. European Journal of Cancer 2020130 198-203. (https://doi.org/10.1016/j. ejca.2020.02.049)

37 Snyders T, Chakos D, Swami U, Latour E, Chen Y, Fleseriu M, Milhem M, Zakharia Y \& Zahr R. Ipilimumab-induced hypophysitis, a single academic center experience. Pituitary 201922 488-496. (https://doi.org/10.1007/s11102-019-00978-4)

38 Lin CH, Chen KH, Chen KY, Shih SR \& Lu JY. Immune checkpoint inhibitor therapy-induced hypophysitis approximately a case series of Taiwanese patients. Journal of the Formosan Medical Association 2019118 524-529. (https://doi.org/10.1016/j.jfma.2018.07.014)

39 Erra A, Pannu BS, Patel S, Qureshi F \& Soliman M. A rare case of ipilimumab-induced reversible hypophysitis and permanent primary hypothyroidism. Cureus 20192019 e5001. (https://doi.org/10.7759/ cureus.5001)

40 Thapi S, Leiter A, Galsky M \& Gallagher EJ. Recovery from secondary adrenal insufficiency in a patient with immune checkpoint inhibitor therapy induced hypophysitis. Journal for ImmunoTherapy of Cancer 20197 248. (https://doi.org/10.1186/s40425-019-0729-3)

41 Agarwal K, Yousaf N \& Morganstein D. Glucocorticoid use and complications following immune checkpoint inhibitor use in melanoma. Clinical Medicine 202020 163-168. (https://doi. org/10.7861/clinmed.2018-0440)

42 Bai X, Chen X, Wu X, Huang Y, Zhuang Y \& Lin X. Immune checkpoint inhibitor-associated thyroid dysfunction: a disproportionality analysis using the WHO Adverse Drug Reaction Database, VigiBase. European Journal of Endocrinology 2020182 1-9. (https://doi.org/10.1530/EJE-19-0535)

43 Morganstein DL, Lai Z, Spain L, Diem S, Levine D, Mace C, Gore M \& Larkin J. Thyroid abnormalities following the use of cytotoxic T-lymphocyte antigen- 4 and programmed death receptor protein-1 inhibitors in the treatment of melanoma. Clinical Endocrinology 2017 86 614-620. (https://doi.org/10.1111/cen.13297)

44 Barroso-Sousa R, Barry WT, Garrido-Castro AC, Hodi FS, Min L, Krop IE \& Tolaney SM. Incidence of endocrine dysfunction following the use of different immune checkpoint inhibitor regimens: a systematic review and meta-analysis. JAMA Oncology 20184 173-182. (https://doi.org/10.1001/jamaoncol.2017.3064)

45 Pollack R, Ashash A, Cahn A, Rottenberg Y, Stern H \& DresnerPollak R. Immune checkpoint inhibitor-induced thyroid dysfunction is associated with higher body mass index. Journal of Clinical Endocrinology and Metabolism 2020105 dgaa458. (https://doi. org/10.1210/clinem/dgaa458)

46 Sbardella E, Tenuta M, Sirgiovanni G, Gianfrilli D, Pozza C, Venneri MA, Cortesi E, Marchetti P, Lenzi A, Gelibter AJ, et al. Thyroid disorders in programmed death 1 inhibitor-treated patients: is previous therapy with tyrosine kinase inhibitors a predisposing factor? Clinical Endocrinology 202092 258-265. (https://doi. org/10.1111/cen.14135)

47 Kurimoto C, Inaba H, Ariyasu H, Iwakura H, Ueda Y, Uraki S, Takeshima K, Furukawa Y, Morita S, Yamamoto Y, et al. Predictive and sensitive biomarkers for thyroid dysfunctions during treatment with immune-checkpoint inhibitors. Cancer Science 2020111 1468-1477. (https://doi.org/10.1111/cas.14363)

48 Frelau A, Palard-Novello X, Jali E, Boussemart L, Dupuy A, James P, Devillers A, Le Jeune F, Edeline J, Lesimple T, et al. Increased thyroid

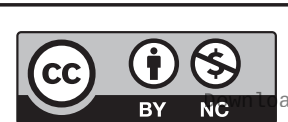

This work is licensed under a Creative Commons Attribution-NonCommercial 4.0 International License. ded from Bioscientifica com at 04/26/2023 02:15:14PM 
uptake on 18F-FDG PET/CT is associated with the development of permanent hypothyroidism in stage IV melanoma patients treated with anti-PD-1 antibodies. Cancer Immunology, Immunotherapy 2020 [epub]. (https://doi.org/10.1007/s00262-020-02712-7)

49 Delivanis DA, Gustafson MP, Bornschlegl S, Merten MM, Kottschade L, Withers S, Dietz AB \& Ryder M. Pembrolizumabinduced thyroiditis: comprehensive clinical review and insights into underlying involved mechanisms. Journal of Clinical Endocrinology and Metabolism 2017102 2770-2780. (https://doi.org/10.1210/ jc.2017-00448)

50 Osorio JC, Ni A, Chaft JE, Pollina R, Kasler MK, Stephens D, Rodriguez C, Cambridge L, Rizvi H, Wolchok JD, et al. Antibodymediated thyroid dysfunction during T-cell checkpoint blockade in patients with non-small-cell lung cancer. Annals of Oncology 201728 583-589. (https://doi.org/10.1093/annonc/mdw640)

51 Yamada H, Okajima F, Onda T, Fujimori S, Emoto N \& Sugihara H. New-onset Graves' disease after the initiation of nivolumab therapy for gastric cancer: a case report. BMC Endocrine Disorders 202020 132. (https://doi.org/10.1186/s12902-020-00613-5)

52 Azmat U, Liebner D, Joehlin-Price A, Agrawal A \& Nabhan F. Treatment of ipilimumab induced Graves' disease in a patient with metastatic melanoma. Case Reports in Endocrinology 20162016 2087525. (https://doi.org/10.1155/2016/2087525)

53 Borodic G, Hinkle DM \& Cia Y. Drug-induced graves disease from CTLA-4 receptor suppression. Ophthalmic Plastic and Reconstructive Surgery 201127 e87-e88. (https://doi.org/10.1097/ IOP.0b013e3181ef72a1)

54 Borodic GE \& Hinkle D. Ipilimumab-induced orbital inflammation resembling Graves disease with subsequent development of systemic hyperthyroidism from CTLA-4 receptor suppression. Ophthalmic Plastic and Reconstructive Surgery 201430 83. (https://doi. org/10.1097/IOP.0000000000000033)

55 Rhea L, Yoon JW \& Jang S. Rapid development of graves' ophthalmopathy after treatment with ipilimumab and recurrence with pembrolizumab in a patient with previously treated Graves' disease. Journal of Oncology Practice 201814 747-749. (https://doi. org/10.1200/JOP.18.00442)

56 Kotwal A, Haddox C, Block M \& Kudva YC. Immune checkpoint inhibitors: an emerging cause of insulin-dependent diabetes. BMJ Open Diabetes Research and Care 20197 e000591. (https://doi. org/10.1136/bmjdrc-2018-000591)

57 Marchand L, Thivolet A, Dalle S, Chikh K, Reffet S, Vouillarmet J, Fabien N, Cugnet-Anceau C \& Thivolet C. Diabetes mellitus induced by PD-1 and PD-L1 inhibitors: description of pancreatic endocrine and exocrine phenotype. Acta Diabetologica 201956 441-448. (https://doi.org/10.1007/s00592-018-1234-8)

58 Stamatouli AM, Quandt Z, Perdigoto AL, Clark PL, Kluger H, Weiss SA, Gettinger S, Sznol M, Young A, Rushakoff R, et al. Collateral damage: insulin-dependent diabetes induced with checkpoint inhibitors. Diabetes 201867 1471-1480. (https://doi. org/10.2337/dbi18-0002)

59 Clotman K, Janssens K, Specenier P, Weets I \& De Block CEM. Programmed cell death-1 (PD-1) inhibitor induced type 1 diabetes mellitus: mini-review. Journal of Clinical Endocrinology and Metabolism 2018103 3144-3154. (https://doi.org/10.1210/jc.201800728)

60 Kyriacou A, Melson E, Chen W \& Kempegowda P. Is immune checkpoint inhibitor-associated diabetes the same as fulminant type 1 diabetes mellitus? Clinical Medicine 202020 417-423. (https://doi. org/10.7861/clinmed.2020-0054)

61 Hughes J, Vudattu N, Sznol M, Gettinger S, Kluger H, Lupsa B \& Herold KC. Precipitation of autoimmune diabetes with anti-PD-1 immunotherapy. Diabetes Care 201538 e55-e57. (https://doi. org/10.2337/dc14-2349)

62 Akturk HK, Kahramangil D, Sarwal A, Hoffecker L, Murad MH \& Michels AW. Immune checkpoint inhibitor-induced Type 1 diabetes: a systematic review and meta-analysis. Diabetic Medicine 201936 1075-1081. (https://doi.org/10.1111/dme.14050)

63 Gaudy C, Clevy C, Monestier S, Dubois N, Preau Y, Mallet S, Richard MA, Grob JJ, Valero R \& Beliard S. Anti-PD1 pembrolizumab can induce exceptional fulminant Type 1 diabetes. Diabetes Care 20152015 e182-e183. (https://doi.org/10.2337/dc151331)

64 Ishikawa K, Shono-Saito T, Yamate T, Kai Y, Sakai T, Shimizu F, Yamada Y, Mori H, Noso S, Ikegami H, et al. A case of fulminant type 1 diabetes mellitus, with a precipitous decrease in pancreatic volume, induced by nivolumab for malignant melanoma: analysis of HLA and CTLA-4 polymorphisms. European Journal of Dermatology 201727 184-185. (https://doi.org/10.1684/ejd.2016.2923)

65 Tsiogka A, Jansky GL, Bauer JW \& Koelblinger P. Fulminant type 1 diabetes after adjuvant ipilimumab therapy in cutaneous melanoma. Melanoma Research 201727 524-525. (https://doi.org/10.1097/ CMR.0000000000000384)

66 Mizab Mellah C, Sanchez Perez M, Santos Rey MD \& Hernandez Garcia M. Fulminant type 1 diabetes mellitus associated with pembrolizumab. Endocrinologia, Diabetes y Nutricion 201764 272-273. (https://doi.org/10.1016/j.endinu.2017.01.005)

67 Takahashi A, Tsutsumida A, Namikawa K \& Yamazaki N. Fulminant type 1 diabetes associated with nivolumab in a patient with metastatic melanoma. Melanoma Research 201828 159-160. (https:// doi.org/10.1097/CMR.0000000000000418)

68 Araujo M, Ligeiro D, Costa L, Marques F, Trindade H, Correia JM \& Fonseca C. A case of fulminant Type 1 diabetes following anti-PD1 immunotherapy in a genetically susceptible patient. Immunotherapy 20179 531-535. (https://doi.org/10.2217/imt-2017-0020)

69 Munakata W, Ohashi K, Yamauchi N \& Tobinai K. Fulminant type I diabetes mellitus associated with nivolumab in a patient with relapsed classical Hodgkin lymphoma. International Journal of Hematology 2017105 383-386. (https://doi.org/10.1007/s12185-0162101-4)

70 Okamoto M, Okamoto M, Gotoh K, Masaki T, Ozeki Y, Ando H, Anai M, Sato A, Yoshida Y, Ueda S, et al. Fulminant type 1 diabetes mellitus with anti-programmed cell death-1 therapy. Journal of Diabetes Investigation 20167 915-918. (https://doi.org/10.1111/ jdi.12531)

71 Lowe JR, Perry DJ, Salama AK, Mathews CE, Moss LG \& Hanks BA. Genetic risk analysis of a patient with fulminant autoimmune type 1 diabetes mellitus secondary to combination ipilimumab and nivolumab immunotherapy. Journal for ImmunoTherapy of Cancer 20164 89. (https://doi.org/10.1186/s40425-016-0196-z)

72 Aleksova J, Lau PK, Soldatos G \& McArthur G. Glucocorticoids did not reverse type 1 diabetes mellitus secondary to pembrolizumab in a patient with metastatic melanoma. BMJ Case Reports 20162016 bcr2016217454. (https://doi.org/10.1136/bcr-2016-217454)

73 Sakai G, Saito D, Nakajima R, Hatano M, Noguchi Y, Kurihara S, Katayama S, Inoue I, Noda M \& Shimada A. Intrinsic insulin secretion capacity might be preserved by discontinuing antiprogrammed cell death protein 1 antibody treatment in 'antiprogrammed cell death protein 1 antibody-induced' fulminant type 1 diabetes. Journal of Diabetes Investigation 20189 448-449. (https:// doi.org/10.1111/jdi.12662)

74 Williams KJ, Grauer DW, Henry DW \& Rockey ML. Corticosteroids for the management of immune-related adverse events in patients receiving checkpoint inhibitors. Journal of Oncology Pharmacy Practice 201925 544-550. (https://doi.org/10.1177/1078155217744872)

75 Cortellini A, Vitale MG, De Galitiis F, Di Pietro FR, Berardi R, Torniai M, De Tursi M, Grassadonia A, Di Marino P, Santini D, et al. Early fatigue in cancer patients receiving PD-1/PD-L1 checkpoint inhibitors: an insight from clinical practice. Journal of Translational Medicine 201917 376. (https://doi.org/10.1186/s12967-019-02132-x)

76 Ajmal A, Mckean E, Sullivan S \& Barkan A. Decreased quality of life (QoL) in hypopituitary patients: involvement of glucocorticoid

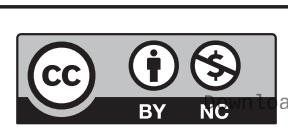

This work is licensed under a Creative Commons Attribution-NonCommercial 4.0 International License. ded from Bioscientifica.com at 04/26/2023 02:15:14PM 
replacement and radiation therapy. Pituitary 201821 624-630. (https://doi.org/10.1007/s11102-018-0918-y)

77 Goldney RD, Phillips PJ, Fisher LJ \& Wilson DH. Diabetes, depression, and quality of life: a population study. Diabetes Care 2004 27 1066-1070. (https://doi.org/10.2337/diacare.27.5.1066)

78 Kotwal A, Kottschade L \& Ryder M. PD-L1 inhibitor-induced thyroiditis is associated with better overall survival in cancer patients. Thyroid 202030 177-184. (https://doi.org/10.1089/ thy.2019.0250)

79 Lima Ferreira J, Costa C, Marques B, Castro S, Victor M, Oliveira J, Santos AP, Sampaio IL, Duarte H, Marques AP, et al. Improved survival in patients with thyroid function test abnormalities secondary to immune-checkpoint inhibitors. Cancer Immunology, Immunotherapy 2020 [epub]. (https://doi.org/10.1007/s00262-02002664-y)

80 Kobayashi T, Iwama S, Yasuda Y, Okada N, Okuji T, Ito M, Onoue T, Goto M, Sugiyama M, Tsunekawa T, et al. Pituitary dysfunction induced by immune checkpoint inhibitors is associated with better overall survival in both malignant melanoma and non-small cell lung carcinoma: a prospective study. Journal for ImmunoTherapy of Cancer 20208 e000779. (https://doi. org/10.1136/jitc-2020-000779)

Received in final form 17 January 2021

Accepted 4 February 2021

Accepted Manuscript published online 6 February 2021
This work is licensed under a Creative Commons Attribution-NonCommercial 4.0 International License. 